\title{
The potential of organometallic complexes in medicinal chemistry
}

\author{
Gasser, Gilles ; Metzler-Nolte, Nils
}

\begin{abstract}
Organometallic complexes have unique physico-chemical properties, which have been widely used in homogenous catalysis, for example, for the synthesis of lead compounds and drug candidates. Over the past two decades, a few scientists from all over the world have extended the use of the specific characteristics of these compounds (e.g. structural diversity, possibility of ligand exchange, redox and catalytic properties) for medicinal purposes. The results are stunning. A few organometallic compounds have already entered clinical trials and it can be anticipated that several more will follow in coming years. In this short review, we present the specific advantages that organometallic metal complexes have over purely organic and also coordination compounds. Furthermore, using specific examples, we illustrate how these particular properties can be put to good use in medicinal chemistry. The examples we present have an emphasis on, but are not restricted to, anti-cancer activity.
\end{abstract}

DOI: https://doi.org/10.1016/j.cbpa.2012.01.013

Posted at the Zurich Open Repository and Archive, University of Zurich

ZORA URL: https://doi.org/10.5167/uzh-69307

Journal Article

Accepted Version

Originally published at:

Gasser, Gilles; Metzler-Nolte, Nils (2012). The potential of organometallic complexes in medicinal chemistry. Current Opinion in Chemical Biology, 16:84-91.

DOI: https://doi.org/10.1016/j.cbpa.2012.01.013 


\title{
The Potential of Organometallic Complexes for
}

\section{Medicinal Chemistry}

\author{
Gilles Gasser ${ }^{a, *}$ and Nils Metzler-Nolte $e^{b, *}$
}

${ }^{a}$ Institute of Inorganic Chemistry, University of Zurich, Winterthurerstrasse 190, CH-8057 Zurich, Switzerland; ${ }^{b}$ Inorganic Chemistry I - Bioinorganic Chemistry, Faculty of Chemistry and Biochemistry, Ruhr-University Bochum, Universitätsstrasse 150, 44801 Bochum, Germany

* Corresponding authors: email: gilles.gasser@aci.uzh.ch. Phone: +41 4463546 30. Fax: +41 44635 68 03. WWW: www.gassergroup.com; Email: nils.metzler-nolte@ rub.de. Phone: +49 2343228152. Fax: +49 234321 4378. WWW : http://www.chemie.ruhr-uni-bochum.de/ac1/. 


\begin{abstract}
Organometallic complexes have unique physico-chemical properties, which have been widely used in homogenous catalysis, e.g. for the synthesis of lead compounds and drug candidates. Over the last two decades, a few scientists from all over the world have extended the use of the specific characteristics of these compounds (e.g. structural diversity, possibility of ligand exchange, redox and catalytic properties) for medicinal purposes. The results are stunning. A few organometallic compounds have already entered clinical trials and it can be anticipated that several more will follow in coming years. In this short review, we present the specific advantages that organometallic metal complexes have over purely organic and also coordination compounds. Furthermore, using specific examples, we illustrate how these particular properties can be put to good use in medicinal chemistry. The examples we present have an emphasis on, but are not restricted to, anti-cancer activity.
\end{abstract}




\section{Introduction}

Chemists and their compounds are without any doubt contributing tremendously to the breathtaking progress of medicine. A view at the periodic table reveals that there are 82 non-radioactive elements, of which more than 60 easily form air- and water-stable covalent, molecular compounds that could potentially be useful in medicinal chemistry. The great majority of all drugs, however, contain only ten of those $>60$ elements. Notably, very few drugs or drug candidates exist that contain any of the transition metals other than platinum.[1,2] On the other hand, it is obvious that organometallic chemistry, which can be classified as the chemistry studying chemical compounds containing at least one metal-carbon bond, is currently much more known for its many applications in catalysis, rather than for applications in medicine. Although the attention given to medicinal organometallic chemistry, which can be defined as the research field involving the use of organometallic compounds for medicinal purposes, has steadily grown over the last years, the importance and reputation of this area of research are still negligible compared to those of catalysis or even biosensing.[3]

We hope to demonstrate to the readers of this article that organometallic compounds possess remarkable physico-chemical properties, which are rather unique and of high interest in a medicinal chemistry context. As described in more detail below, spectacular advances have been recently made in this field of research despite only "polite" interest from both the pharmaceutical industry and academia. A few organometallic compounds have even entered into clinical trials and metal-specific modes of action have been lately uncovered![4] Importantly, these compounds have the potential in various areas of medicine to serve as anticancer, antimalarial, antimicrobial or diagnostic agents.

In this contribution, we will not review all the latest developments in medicinal organometallic chemistry as this has been recently performed.[5-9] We will rather highlight the specific properties / advantages (e.g. structural diversity, possibility of ligand exchange, redox and catalytic properties, etc...), that organometallics have over purely organic compounds and exemplify them with one or two concrete examples. 


\section{Structural Diversity}

A carbon atom with four different substituents may occur in two different enantiomers, which are not superimposable. In contrast, an octahedral transition metal complex with six substituents has 30 different stereoisomers! If we take the central atom (carbon or transition metal) simply as a template that will orient its substituents in three-dimensional space then clearly, the structural diversity in typical transition metal complexes exceeds that of purely organic compounds. Parallel to organic compounds, racemization is unlikely to occur in kinetically inert transition metal complexes, i.e. the positioning of the ligands around the metal center must be stereochemically stable. This requirement is not equally well met by all transition metals, and conformational stability may in addition be a function of the oxidation state of the metal. In general, transition metals of the second and third row with closed electron shells are most suited, such as $\mathrm{Ru}(\mathrm{II})$, Os(II) or Ir(III) and therefore have been most frequently used in medicinal inorganic chemistry when structurally rigid compounds were required.

Meggers and coworkers have used structurally inert $\mathrm{Ru}(\mathrm{II})$ complexes to design inhibitors of protein kinases.[10-12] These proteins are known to have a multitude of important functions in the body and are therefore valuable targets to modify e.g. signalling pathways within malignant cells. This work was inspired by the natural product staurosporin, which inhibits kinases by competitively binding to the ATP binding site. Figure 1 depicts the similar binding mode of metallo-pyridocarbazole complexes to the ATP binding site, and the structure of one Ru-based metal complex 1 (FL-411) as an example. Generally, the Ru-containing degradation products are assumed to have a low metal-based toxicity and the synthetic chemistry of these complexes is very well established, giving access to a huge variety of compounds. This provides great opportunities for the design of selective kinase inhibitors, which should target one of the 518 different kinases that are encoded in the human genome.[13] To date, almost a dozen co-crystal structures with metal complexes as inhibitors provide an excellent structural basis for the remarkable selectivity of the identified metal complexes, some of which have as low as pM affinity to one specific kinase in vitro. Since the Ru complexes described above are generally 
stable to air and water, and even withstand exposure to $\mathrm{mM}$ concentrations of biological ligands such as glutathione, they can readily be tested in vivo. For example, the effect of inhibiting the kinase GSK3 with complex 2 , which in turn switches on the wnt signalling pathway, has been demonstrated in vivo by the development of a hyperdorsalized phenotype in Xenopus laevis embryos.[14] Intriguingly, almost exactly the same anti-proliferative activity is observed for the complex DW12(Ru / Os) regardless of whether the central atom is Os or Ru.[15] This nicely emphasizes the purely structural role played by the metal centres in such complexes.
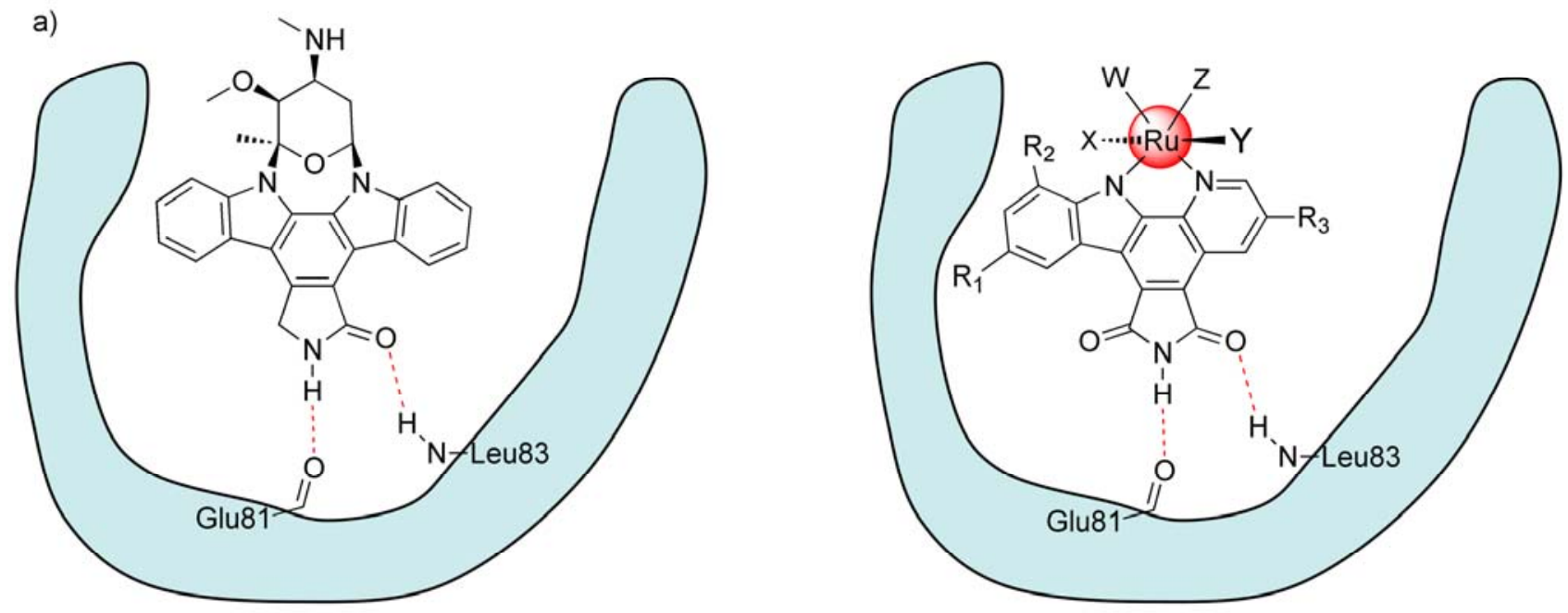

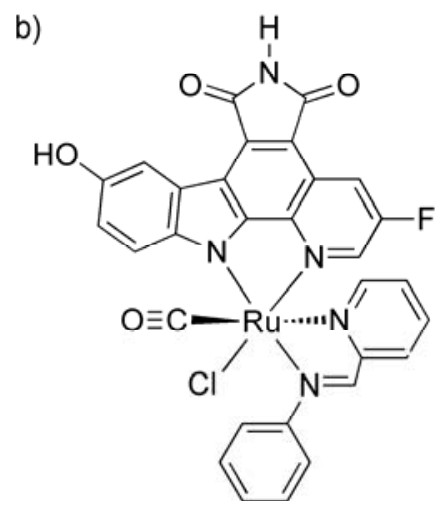

1

(FL-411)

$\mathrm{IC}_{50}(\mathrm{PAK}-1)=110 \mathrm{nM}(1 \mu \mathrm{M}$ ATP $)$

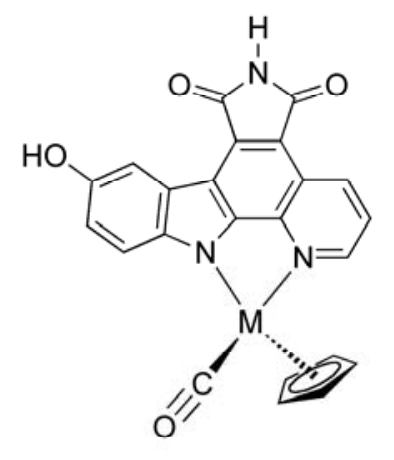

2

$(\mathrm{DW}-12)$ $\mathrm{M}=\mathrm{Ru}$ or Os
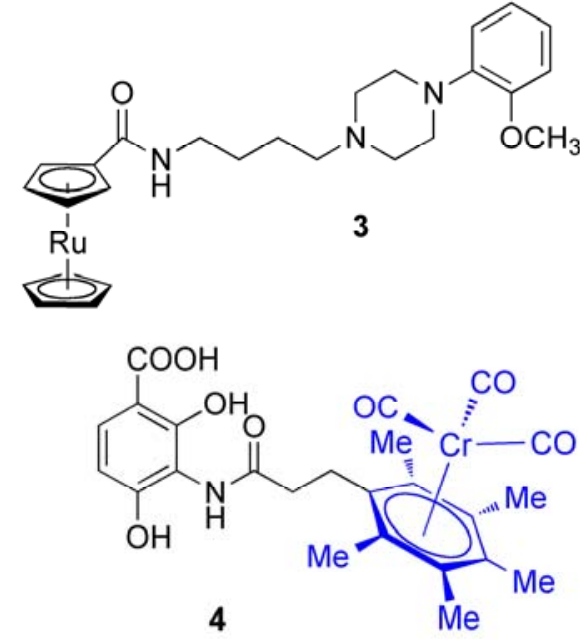

Figure 1. a) The binding motif of the natural product staurosporine to the ATP binding site in kinases (magenta), and the binding of octahedral metal complexes to the same site. b) Two metal-based kinase inhibitors from Meggers' group (1 and 2), a dopamine D4 subtype-specific agonist containing a 
ruthenocene (3), and a chromium-containing platensimycin analogue (4). In 4, the chromium tricarbonyl moiety in blue replaces a multi-cyclic organic group with six stereocenters.

The concept of bio-isosteric replacement of organic groups with metal complexes has been used in other fields of medicinal organometallic chemistry as well. First, Gmeiner's group has exploited organometallic $\mathrm{Ru}$ complexes for dopamine receptor targeting. They found that a ruthenium metallocene derivative 3 (Figure 1) has a $\mathrm{nM}$ affinity for the G-protein coupled receptors such as dopamine and serotonin receptors, and provides unique D4-selective agonist properties.[16] In our work, different organometallic complexes were used as organometallic analogues of platensimycin, an interesting natural compound with anti-bacterial activity. The antibacterial activity of platensimycin is attributed to inhibition of fatty acid biosynthesis in bacteria, especially inhibition of FabF and FabH enzymes. While a range of ferrocene derivatives provided interesting insights into structure-activity relationships (SAR), [17,18] an arene chromium tricarbonyl derivative (4, Figure 1) was the most active compound.[19] Molecular docking experiments showed this compound to fit well into the active pocket of the FabF enzyme. Proteomic studies, on the other hand, indicated a mechanism of action for 4 that is different from inhibition of fatty acid biosynthesis and as yet has not been linked to a single molecular target.[20] 


\section{Redox Properties}

In the previous section, we discussed metal complexes which were completely inert, and in which the metal center had a purely structural role. However, many metal complexes will readily undergo electron transfer reactions, as it is well known for many enzymes and cofactors, e.g. cytochromes and the Fe-S clusters. It has only recently been realized that such redox activity may be highly beneficial for the medicinal activity of the metal complex.

One prominent example comes from Jaouen's group. Using the idea of a "bio-isosteric" replacement of phenyl rings with metallocene fragments, they produced a series of derivatives of the well-known anticancer drug tamoxifen.[21] While most derivatives were rather inactive, the ferrocene derivatives (later called "ferrocifens", see compound $\mathbf{5}$ in Figure 2 as an example) did not only show an activity comparable to tamoxifen itself, but some additional, remarkable features.[22] Tamoxifen is the firstline treatment for breast cancer. The drug binds competitively to the estrogen receptor $\alpha$ subtype $(\mathrm{ER} \alpha)$, thereby repressing estradiol-mediated DNA transcription in tumor cells. It follows that tamoxifen and related compounds will only be active against those types of breast cancer which overexpress the ER $\alpha$. Unfortunately, this is not the case for about one third of all breast cancer patients and indeed, those without ER $\alpha$ overexpression have a significantly worse prognosis. Much to the surprise of the researchers, certain ferrocifens were similarly active against all breast cancer cell lines, including the ER $\alpha$-negative ones. Careful further experiments revealed that the activity is linked to reversible redox behaviour of the iron center in these compounds. A mechanism was proposed by which oxidation of $\mathrm{Fe}(\mathrm{II})$ to $\mathrm{Fe}(\mathrm{III})$ in the ferrocene core initiates proton-coupled electron abstraction in the organic part, eventually leading to oxidation of the phenolic part to a quinone methide.[23] Already in tamoxifen, the formation of quinone methides, which are thought to react with thiols and nucleobases in vivo, has been proposed as vital for activity of the drug. Because of the fast and reversible formation of $\mathrm{Fe}(\mathrm{III})$ species, the metallocene is thought to act as a "redox antenna", thereby offering an alternative mode of action for the ferrocifens beyond estrogen receptor binding.[24] 
Interesting experimental support for this proposal comes from $\mathrm{Ru}$ analogues of ferrocifen. These compounds do exhibit tamoxifen-type activity against ER $\alpha$-positive cancer cells, but like tamoxifen itself are inactive against ER $\alpha$-negative cell lines. While the overall size and shape of ruthenocene is indeed very similar to ferrocene, its electrochemistry is drastically different, with higher redox potential and most importantly, no reversibility for the electron transfer reaction. Hence, in contrast to the kinase inhibitors described above, where exchanging structurally similar metal ions supports the notion of a purely structural role for the metal ions, the ferrocifen story provides an example where indeed redox activity of the metal is crucial, and iso-structural replacement of metal ions may indeed kill the activity of the compound if it alters the redox properties of the compound.[25]

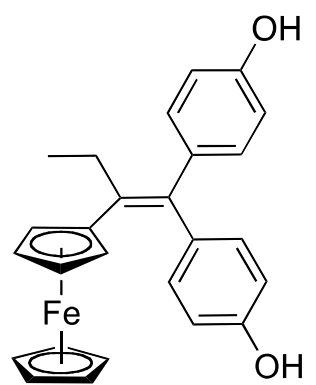

5

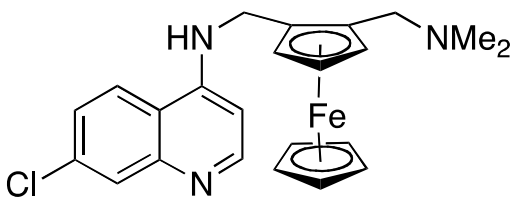

6

Figure 2. An active and more versatile analogue of the anti-tumor drug tamoxifen (ferrocifen, 5), and ferroquine (6), an anti-malarial drug candidate in clinical trials that does not develop cross-resistance with chloroquine.

It seems that redox activity of iron in a ferrocene derivative also plays a role in an analogue of the wellknown anti-malarial drug candidate chloroquine, namely ferroquine 6 (Figure 2), although other factors seem to play a role as well. The reader is referred to a rather comprehensive recent article on ferroquine, which at the moment is the most advanced organometallic drug candidate, soon to enter clinical phase III trials.[26] 


\section{Ligand Exchange}

The ability of metal complexes to undergo ligand exchange "for medicinal purposes" is notorious and cisplatin is probably the best example to illustrate it.[27,28] This aptitude towards ligand exchange is not limited to coordination complexes alone. Organometallic compounds can undergo a similar ligand exchange. As outlined below, this leads to applications in diverse areas of medicinal chemistry, but predominantly for the preparation of novel chemotherapeutic agents. Indeed, several organometallic compounds are thought to exert, at least partially, their antiproliferative activity through a ligand exchange mechanism.[3,6,29-31] In this section, we will only highlight two examples where the cellular targets of the organometallic anticancer compounds are different despite the fact that the mode of action of both derivatives seems to involve a related ligand exchange process. To date, besides the ferrocifens mentioned above,[22] organogold compounds [32] and titanocene derivatives,[33] the most studied examples of organometallic anticancer compounds are Ru-arene derivatives. These compounds are developed independently by the Sadler[34] (Scheme 1a) and Dyson[35] (Scheme 1c) research groups. Interestingly, despite their strong structural resemblance and the ability of both derivatives to (potentially) undergo ligand exchange, it is believed that these two types of half-sandwich "pianostool" organometallics have a very different mechanism of action. The one for compounds of the type $\left[\left(\eta^{6} \text {-arene }\right) \mathrm{Ru}(\mathrm{en})(\mathrm{Cl})\right]^{+}(\mathrm{en}=$ ethylenediamine $)$ is reminiscent of that of cisplatin and involves, first, the substitution of the chloride anion by a water molecule (Scheme 1a). The new aqua species formed then binds to nuclear DNA with a high affinity for the N7 position of guanine bases.[3,36-38] The similarity to the mode of action of cisplatin stops at this point as only monoadducts with DNA can be formed with these derivatives, contrasting to cisplatin which forms bifunctional adducts and DNA cross-links. It is also important to highlight the fact that these $\left[\left(\eta^{6} \text {-arene }\right) \mathrm{Ru}(\mathrm{en})(\mathrm{Cl})\right]^{+}$derivatives are active against cisplatin-resistant cell lines suggesting that at least the detoxification mechanism is different that of cisplatin.[3,39] By comparison, the in vivo behaviour of RAPTA-C and RAPTA-T (RA stands for Ruthenium-Arene and PTA for the 1,3,4-triaza-7-phosphatricyclo-[3.3.1.1]decane 
ligand, see Scheme 1c) is strongly different. They can indeed selectively reduce the weight and number of lung metastases of CBA mice bearing the MCa mammary carcinoma with only mild effects on the primary tumour. Interestingly, hydrolysis does not seem to be required for these compounds to exert their activity, although ligand exchange still occurs and seems to contribute to their cytotoxic activity. It has been indeed demonstrated that even in blood plasma, where the chloride concentration is high enough to avoid the hydrolysis of the dichloride-containing RAPTA compounds, these Ru complexes bind to serum protein.[30] Other experimental observations provide strong evidence that the hydrolysis step is not required: RAPTA compounds, whose chloride ligands have been replaced with dicarboxylate ligands and which resist hydrolysis (e.g. oxalo-RAPTA-C in Scheme 1c), still exerts a similar in vitro activity as the parent compound RAPTA-C! All evidence taken together, it is now thought that RAPTA complexes bind not to DNA but rather to proteins and particularly to cathepsin B (cat B) by different interactions, notably by binding to the sulphur atom of a cysteine present in the active site of the enzyme (Scheme 1b). It seems that the particular properties of the PTA ligand do also contribute to these notable differences.

It is worth mentioning that the ability of organometallics to undergo ligand exchange has found application in areas other than chemotherapeutic treatment. Hence, different metal (e.g. Au, Ag, Rh and $\mathrm{Ru})$ carbene compounds have very promising antimicrobial activity.[40-43] All in all, the examples shown above demonstrate clearly that organometallic compounds possess outstanding properties to be used in medicinal chemistry development due, notably, to their ability to strongly bind target through a coordinative bond. 
a)

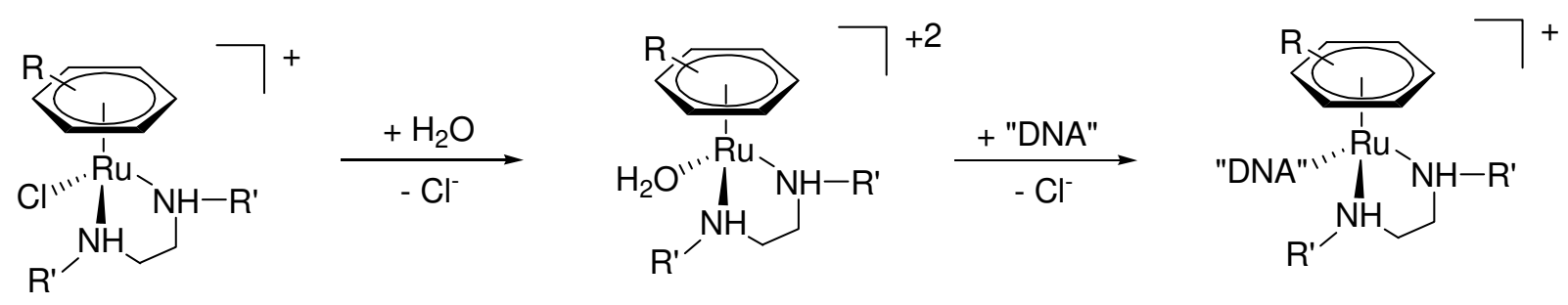

$\mathrm{Ru}^{\prime \prime}$ arene ethylenediamine derivatives

b)

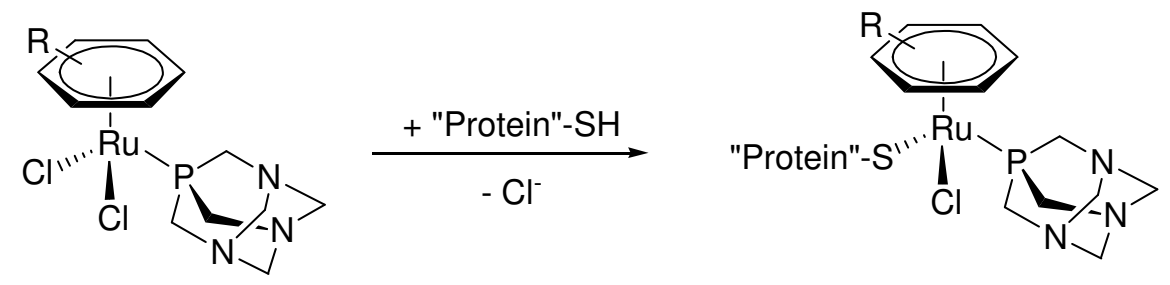

RAPTA Derivatives

c)

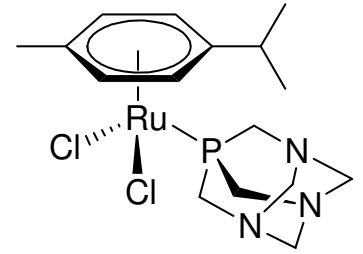

RAPTA-C

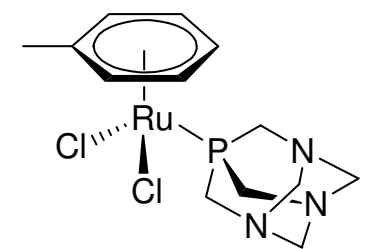

RAPTA-T

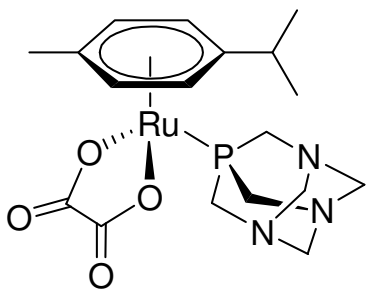

oxalo-RAPTA-C

Scheme 1. a) Simplistic representation of the mechanism of action of $\mathrm{Ru}^{\mathrm{II}}$ arene ethylenediamine and b) RAPTA derivatives, highlighting the different biological targets of the two types of compounds; c) Structures of RAPTA-C, RAPTA-T and oxalo-RAPTA-C.

Beside the examples described above, the ability of organometallics to undergo ligand exchange can lead to further interesting applications in medicine. Indeed, instead of exchanging a "useless" ligand (e.g. $\mathrm{Cl}^{-}$, etc...) by a biomolecule (e.g. DNA, protein, etc...) to form a novel metal adduct, which will interrupt the proper function of this precise biomolecule, the released ligand can be actually a molecule 
with a medicinal effect of its own, as for example, carbon monoxide (CO).[44] Indeed, despite its bad reputation as the "silent killer", the beneficial therapeutic effects of $\mathrm{CO}$ as a small messenger molecule similar to NO are extremely diverse. They include, for example, the reduction of inflammation, the suppression of organ graft rejection or the protection of the heart during reperfusion after cardiopulmonary bypass surgery.[45-47] Naturally, the use of gaseous CO causes obvious problems linked to its safe handling as well as its selective and specific delivery to a specific part of the body.[47] CO-releasing molecules, often abbreviated CORMs, are therefore an attractive alternative to the administration of CO gas. However, as emphasised by Motterlini and Otterbein in 2010, the chances to see any of the CORMs reported so far to reach the clinic are low.[46] These compounds lack the drug-like properties necessary for a pharmaceutically acceptable medicine.[46] In this context, Zobi et al. envisaged the use of cyanocobalamine (vitamin $\mathrm{B}_{12}$ ) as a biocompatible scaffold for rhenium-containing CORMs. An important argument for the use of such organometallic complexes is that the resulting oxidised product after $\mathrm{CO}$ release, namely rhenium pertechnetate $\mathrm{ReO}_{4}{ }^{-}$, is one of the least toxic of the rarest inorganic compounds.[47] Their two Re-vitamin $B_{12}$ bioconjugates (e.g. $\mathbf{B}_{\mathbf{1 2}^{-}}$ $\operatorname{ReBr}_{2}(\mathbf{C O})_{2} \mathbf{H}_{2} \mathbf{O}$, Figure 3) were shown to have favourable half-lives for biological/medicinal applications and to protect heart tissue from ischaemia-reperfusion injury.[47] As outlined by the authors, all Re bioconjugates in this paper have better features than their parent complexes.[48] They are more water soluble, more stable in aqueous aerobic media and biocompatible.[47] Furthermore, the therapeutic potential of these compounds seems extremely large. As Vitamin $\mathrm{B}_{12}$ is stored and processed in the liver, one could think that these rhenium bioconjugates could be useful for the treatment of liver inflammation. They could also be given to patients with liver transplants as it has been shown that $\mathrm{CO}$ helps to suppress organ rejections.[45,46] 
a)

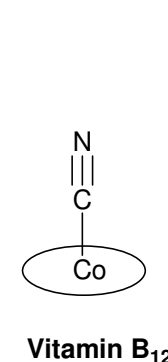

b)

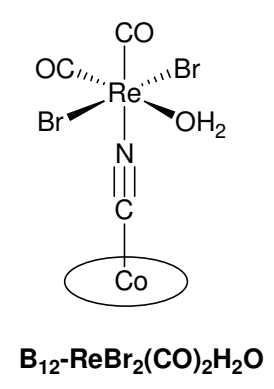

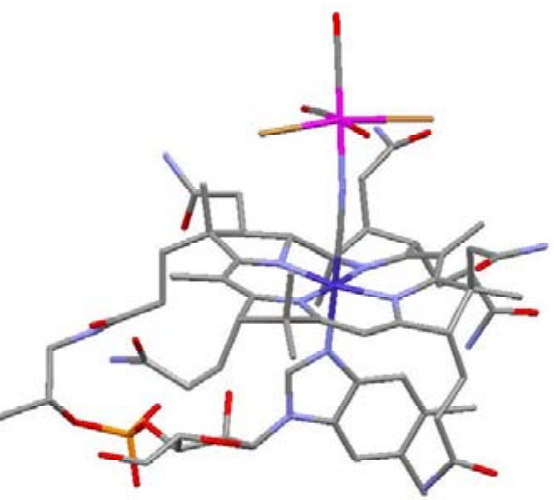

Figure 3. a) Schematic structures of vitamin $B_{12}$ and its rhenium complex $\mathbf{B}_{\mathbf{1 2}}-\operatorname{ReBr}_{\mathbf{2}}(\mathbf{C O})_{\mathbf{2}} \mathbf{H}_{\mathbf{2}} \mathbf{O}$; b) DFT calculated structure of $\mathbf{B}_{12}-\operatorname{ReBr}_{2}(\mathbf{C O})_{2} \mathbf{H}_{2} \mathbf{O}$. H atoms are omitted for clarity. Line drawing structure created from data provided by Dr. Fabio Zobi with the help of the Mercury Program. 


\section{Catalytic Properties}

A physico-chemical property of organometallic compounds which has been certainly, up to now, underestimated for its potential in medicinal chemistry and chemical biology is the ability of such derivatives to catalyse chemical reactions. In this perspective, the recent results obtained by Sadler and co-workers with half-sandwich "piano-stool" ruthenium arene complexes are definitively a step forward towards the design of catalytic drugs. Indeed, they found that relatively hydrolytically inert $\mathrm{Ru}$ organometallics complexes such as 7 (Scheme 2) were still highly toxic towards human ovarian A2780 and human lung A549 cancer cells.[49] The mechanism of action of these compounds has been associated with an increase of reactive oxidative species (ROS). The authors have proposed a redox catalytic cycle involving gluthatione attack on the azo bond of coordinated azopyridine to explain the cytotoxic effect of these $\mathrm{Ru}$ complexes (Scheme 2).[49] Of note, the azopyridine ligand alone is difficult to reduce. However, upon coordination to the $\mathrm{Ru}$ centre, the reduction potential of the ligand becomes biologically accessible. It should also be pointed out that the ferrocenyl moiety of the antimalarial compound ferroquine (see above) has been also found to be responsible of the formation of ROS. All in all, we strongly believe that these examples will pioneer a new area in the design of organometallic anticancer compounds. 


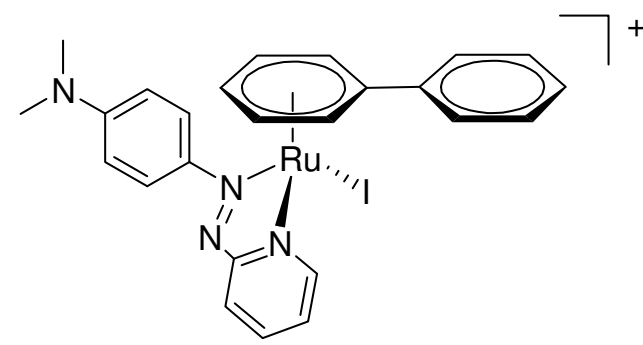

7
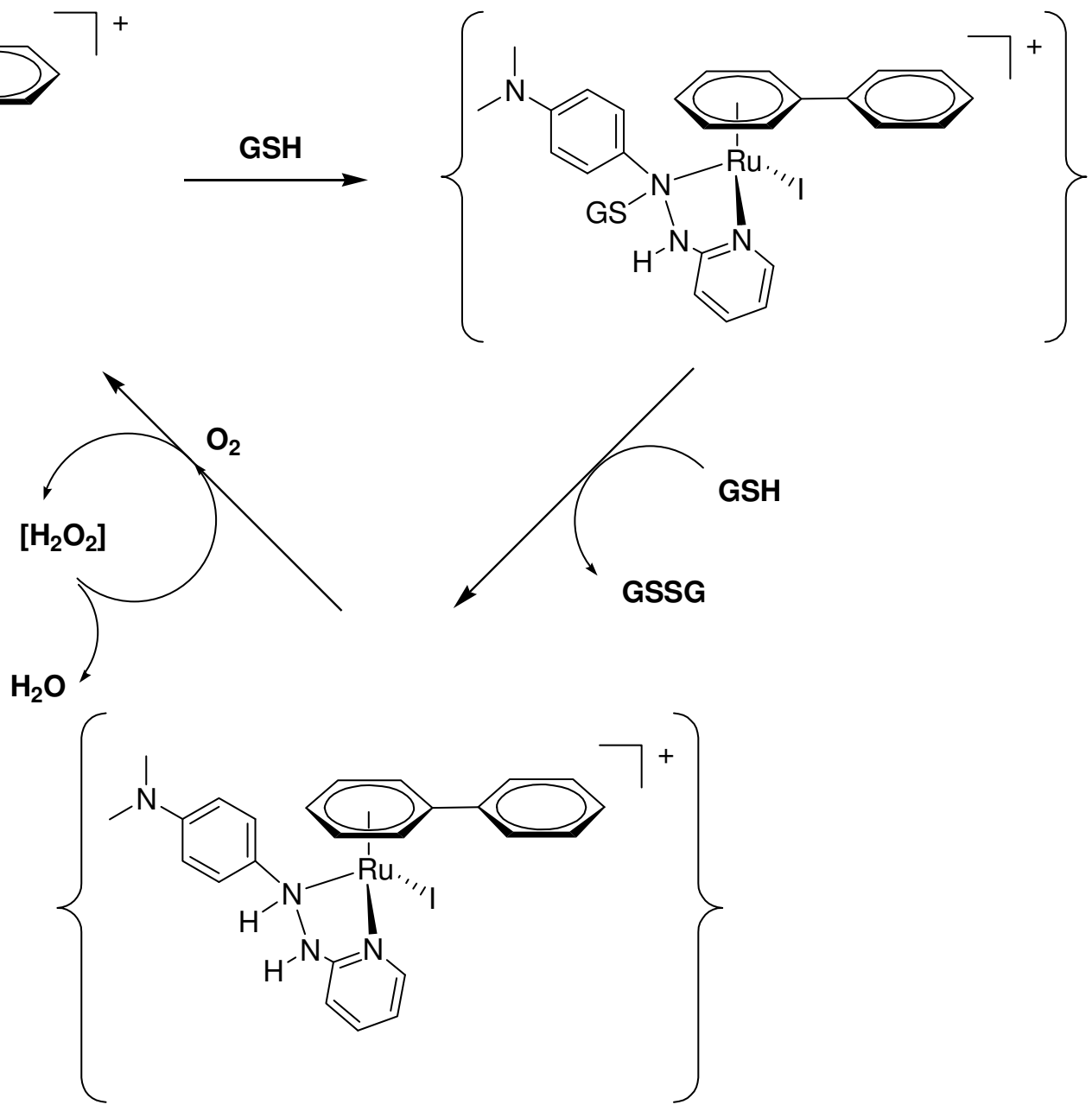<smiles>N[C@@H](CCC(=O)NC(CS)C(=O)NCC(=O)O)C(=O)O</smiles>

Scheme 2. Proposed redox catalytic cycle explaining the cytotoxic effect of inert Ru-arene complexes using 7 as an example. Scheme adapted from ref.[29,49]. 


\section{Conclusions}

Although spectacular advances have been recently made in medicinal organometallic chemistry, we do think that the full potential of these compounds has not yet been realized. One area which was not mentioned above is metal-based radiopharmaceuticals. Across the periodic table, several isotopes exist of all transition metals, of which some can be used for both radioimaging and radiotherapy.[50] Even beyond radiopharmaceuticals, it seems that the specific properties of organometallic drug candidates have by far not been fully exploited. Organometallics provide a great structural variety (ranging from linear to octahedral and even beyond) and a far more diverse stereochemistry than organic compounds, as described in the section on structural variations above. Rational ligand design offers to the medicinal chemist control over kinetic properties, such as the rate of ligand exchange (see above). Furthermore, they are kinetically stable, usually uncharged with the metal atom in a low oxidation state, relatively lipophilic, and amenable to a host of standard chemical transformations. Once the full potential of organometallics unfolds in the hands of medicinal chemists, we can expect some further stunning discoveries, which, once translated into drugs, will ultimately benefit patients as well.

\section{Acknowledgments}

This work was supported by the Swiss National Science Foundation (Professorship $\mathrm{N}^{\circ}$ PP00P2_133568 to G.G.), the University of Zurich, the Research Department Interfacial Systems Chemistry and the DFG through the Research Unit "Biological Function of Organometallic Compounds" (FOR 630, www.rub.de/for630). We thank Dr. Fabio Zobi and Dr. Malay Patra for helpful discussions. 
References and recommended reading

- Papers of special interest

1. Gielen M, Tiekink ERT: Metallotherapeutic Drugs \& Metal-based Diagnostic Agents. Chichester: John Wiley \& Sons, Ltd.; 2005.

- This book describes the advances in the field of medicinal inorganic chemistry element by element.

2. Alessio E (Ed): Bioinorganic Medicinal Chemistry Weinheim: Wiley-VCh; 2011.

- Contrary to reference 1 , this book presents the field of medicinal inorganic chemistry by concepts and contains more recent information.

3. Gasser G, Ott I, Metzler-Nolte N: Organometallic Anticancer Compounds. J. Med. Chem. 2011, 54:3-25, and references therein.

- This is probably the most complete review about organometallic compounds with antiproliferative activity.

4. Gianferrara T, Bratsos I, Alessio E: A categorization of metal anticancer compounds based on their mode of action. Dalton Trans. 2009:7588-7598.

5. Jaouen G, Metzler-Nolte N: Medicinal Organometallic Chemistry. In Topics in Organometallic Chemistry. Edited by: Springer-Verlag; 2010. vol 32.]

- This book contains the most updated information on the field of medicinal organometallic chemistry.

6. Hartinger C, Dyson PJ: Bioorganometallic chemistry - from teaching paradigms to medicinal applications. Chem. Soc. Rev. 2009, 38:391-401.

7. Ronconi L, Sadler PJ: Using coordination chemistry to design new medicines. Coord. Chem. Rev. 2007, 251:1633-1648

8. Smith GS, Therrien B: Targeted and multifunctional arene ruthenium chemotherapeutics. Dalton Trans. 2011:DOI: 10.1039/c1031dt11007a.

9. Jaouen G, Dyson PJ: Medicinal Organometallic Chemistry. In Comprehensive Organometallic Chemistry III, From Fundamentals to Applications Edited by Crabtree RH, Mingos DMP: Elsevier; 2007:445-464. vol 12.]

10. Meggers E: Targeting proteins with metal complexes. Chem. Comm. 2009:1001-1010, and references therein.

11. Mulcahy SP, Meggers E: Organometallics as Structural Scaffolds for Enzyme Inhibitor Design. In Medicinal Organometallic Chemistry. Edited by Jaouen G, Metzler-Nolte N: SpringerVerlag; 2010:141-153. Topics in Organometallic Chemistry, vol 32.]

- This book chapter highlights the recent advances on the use of organometallic compounds as enzyme inhibitors. It shows very nicely that the metal ion of such compounds can have a solely structural role.

12. Gasser G, Metzler-Nolte N: Metal Compounds as Enzyme Inhibitors. In Bioinorganic Medicinal Chemistry. Edited by Alessio E: Wiley-VCH Verlag; 2011:351-382.

13. Meggers E: Exploring biologically relevant chemical space with metal complexes. Current Opinion in Chemical Biology 2007, 11:287-292.

14. Williams DS, Atilla GE, Bregman H, Arzoumanian A, Klein PS, Meggers E: Switching on a Signaling Pathway with an Organoruthenium Complex. Angew. Chem. Int. Ed. 2005, 44:19841987.

15. Maksimoska J, Williams DS, Atilla-Gokcumen GE, Smalley KSM, Carroll PL, Webster RD, Filippakopoulos P, Knapp S, Herlyn M, Meggers E: Similar biological activities of two isostructural ruthenium and osmium complexes. Chem. Eur. J. 2008, 14:4816-4822.

16. Schlotter K, Boeckler F, Hübner H, Gmeiner P: Fancy Bioisosteres: Metallocene-Derived GProtein-Coupled Receptor Ligands with Subnanomolar Binding Affinity and Novel Selectivity Profiles. J. Med. Chem. 2005, 48:3696-3699. 
17. Patra M, Gasser G, Wenzel M, Merz K, Bandow JE, Metzler-Nolte N: Synthesis and Biological Evaluation of Ferrocene-containing Bioorganometallics Inspired by the Antibiotic Platensimycin Lead Structure. Organometallics 2010, 29:4312-4319.

18. Patra M, Gasser G, Wenzel M, Merz K, Bandow JE, Metzler-Nolte N: Synthesis of Optically Active Ferrocene-Containing Platensimycin Derivatives with a C6-C7 Substitution Pattern. Eur. J. Inorg. Chem. 2011:3295-3302.

19. Patra M, Gasser G, Pinto A, Merz K, Ott I, Bandow JE, Metzler-Nolte N: Synthesis and Biological Evaluation of Chromium Bioorganometallics Based on the Antibiotic Platensimycin Lead Structure. ChemMedChem 2009, 4:1930-1938.

20. Wenzel M, Patra M, Albrecht D, Chen DY-K, Nicolaou KC, Metzler-Nolte N, Bandow JE: Proteomic signature of fatty acid biosynthesis inhibition available for in vivo mechanism-ofaction studies. Antimicrob. Agents. Chemother. 2011, 55:2590-2596.

21. Vessieres A, Top S, Pigeon P, Hillard E, Boubeker L, Spera D, Jaouen G: Modification of the Estrogenic Properties of Diphenols by the Incorporation of Ferrocene. Generation of Antiproliferative Effects in Vitro. J. Med. Chem. 2005, 48:3937-3940.

- This is the first paper describing in detail the activity of the so-called "Ferrocifens".

22. Hillard EA, Vessières A, Jaouen G: Ferrocene Functionalized Endocrine Modulators as Anticancer Agents. In Medicinal Organometallic Chemistry. Edited by Jaouen G, Metzler-Nolte N: Springer-Verlag; 2010:81-117. Topics in Organometallic Chemistry, vol 32.]

23. Hillard E, Vessières A, Thouin L, Jaouen G, Amatore C: Ferrocene-mediated proton-coupled electron transfer in a series of ferrocifen-type breast-cancer drug candidates. Angew. Chem. Int. Ed. 2006, 45:285-290.

24. Hamels D, Dansette PM, Hillard EA, Top S, Vessieres A, Herson P, Jaouen G, Mansuy D: Ferrocenyl Quinone Methides as Strong Antiproliferative Agents: Formation by Metabolic and Chemical Oxidation of Ferrocenyl Phenols. Angew. Chem. Int. Ed. 2009, 48:9124-9126.

25. Schatzschneider U, Metzler-Nolte N: New principles in medicinal organometallic chemistry. Angew. Chem. Int. Ed. 2006, 45:1504-1507.

26. Biot C, Dive D: Bioorganometallic Chemistry and Malaria. In Medicinal Organometallic Chemistry. Edited by Jaouen G, Metzler-Nolte N: Springer-Verlag; 2010:155-193. Topics in Organometallic Chemistry, vol 32.]

- This book chapter is a recent summary describing in detail the mode of action of the most advanced organometallic antimalarial agent in clinical trial, namely Ferroquine.

27. Wang D, Lippard SJ: Cellular processing of platinum anticancer drugs. Nat. Rev. Drug. Discov. 2005, 4:307-320.

28. Lippert B: Cisplatin, Chemistry and Biochemistry of a Leading Anticancer Drug. Zürich: Verlag Helvetica Chimica Acta; 1999.

29. Pizarro AM, Habtermariam A, Sadler PJ: Activation Mechanism for Organometallic Anticancer Complexes. In Medicinal Organometallic Chemistry. Edited by Jaouen G, Metzler-Nolte N: Springer-Verlag; 2010:21-56, and references therein. Topics in Organometallic Chemistry, vol 32.]

30. Casini A, Hartinger CG, Nazarov AA, Dyson PJ: Organometallic antitumour agents with alternative mode of action. In Medicinal Inorganic Chemistry. Edited by Jaouen G, MetzlerNolte N: Springer-Verlag; 2010:57-80. Topics in Organometallic Chemistry, vol 32.]

31. Bratsos I, Gianferrara T, Alessio E, Hartinger CG, Jakupec MA, Keppler BK: Ruthenium and Other Non-platinum Anticancer Compounds. In Bioinorganic Medicinal Chemistry. Edited by Alessio E: Wiley-VCH; 2011:151-174.

32. Berners-Price SJ: Gold-Based Therapeutic Agents: A New Perspective. In Bioinorganic Medicinal Chemistry. Edited by Alessio E: Wiley-VCH; 2011:197-222. 
33. Hogan M, Tacke M: Titanocenes: Cytotoxic and Anti-angiogenic Chemotherapy Against Advanced Renal-Cell Cancer. In Medicinal Organometallic Chemistry. Edited by Jaouen G, Metzler-Nolte N: Springer-Verlag; 2010:119-140. Topics in Organometallic Chemistry, vol 32.]

34. Morris RE, Aird RE, Murdoch PdS, Chen H, Cummings J, Hughes NH, Parsons S, Parkin A, Boyd G, Jodrell DI, et al.: Inhibition of Cancer Cell Growth by Ruthenium(II) Arene Complexes. $J$. Med. Chem. 2001, 44:3616-3621.

- This paper by Sadler et al. is one of the first examples of the successful use of Ru-arene compounds for anticancer purposes.

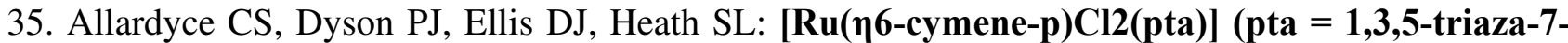
phosphatricyclo[3.3.1.1]decane): a water soluble compound that exhibits pH dependent DNA binding providing selectivity for diseased cells. Chem. Comm. 2001:1396-1397.

- This article by Dyson et al. is the first of a long and successful series of reports about their RAPTA compounds.

36. Novakova O, Chen $\mathrm{H}$, Vrana O, Rodger A, Sadler PJ, Brabec V: DNA Interactions of Monofunctional Organometallic Ruthenium(II) Antitumor Complexes in Cell-free Media. Biochemistry 2003, 42:11544-11554.

37. Liu H-K, Wang F, Parkinson JA, Bella J, Sadler PJ: Ruthenation of duplex and single-stranded d(CGGCCG) by organometallic anticancer complexes. Chem. Eur. J. 2006, 12:6151-6165.

38. Wang F, Xu J, Habtemariam A, Bella J, Sadler PJ: Competition between Glutathione and Guanine for a Ruthenium(II) Arene Anticancer Complex: Detection of a Sulfenato Intermediate. J. Am. Chem. Soc. 2005, 127:17734-17743.

39. Aird RE, Cummings J, Ritchie AA, Muir M, Morris RE, Chen H, Sadler PJ, Jodrell DI: In vitro and in vivo activity and cross resistance profiles of novel ruthenium (II) organometallic arene complexes in human ovarian cancer. Br. J. Cancer 2002, 86:1652-1657.

40. Cannon CL, Hogue LA, Vajravelu RK, Capps GH, Ibricevic A, Hindi KM, Kascatan-Nebioglu A, Walter MJ, Brody SL, Youngs WJ: In Vitro and Murine Efficacy and Toxicity Studies of Nebulized SCC1, a Methylated Caffeine-Silver(I) Complex, for Treatment of Pulmonary Infections Antimicrob. Agents Chemother. 2009, 53:3285-3293.

41. Youngs WJ, Knapp AR, Wagers PO, Tessier CA: Nanoparticle encapsulated silver carbene complexes and their antimicrobial and anticancer properties: A perspective. Dalton Trans. 2012:DOI: 10.1039/c1031dt11100k, and references therein.

42. Melaiye A, Sun Z, Hindi K, Milsted A, Ely D, Reneker DH, Tessier CA, Youngs WJ: Silver(I)-Imidazole Cyclophane gem-Diol Complexes Encapsulated by Electrospun Tecophilic Nanofibers: Formation of Nanosilver Particles and Antimicrobial Activity. J. Am. Chem. Soc. 2005, 127:2285-2291.

43. Hindi KM, Panzner MJ, Tessier CA, Cannon CL, Youngs WJ: The Medicinal Applications of Imidazolium Carbene-Metal Complexes. Chem. Rev. 2009:3859-3884, and references therein.

44. Mann BE, Motterlini R: CO and NO in medicine. Chem. Comm. 2007:4197-4208, and references therein.

45. Mann BE: Carbon Monoxide: An Essential Signaliing Molecule. In Medicinal Organometallic Chemistry. Edited by Jaouen G, Metzler-Nolte N: Springer-Verlag; 2010:247-285. Topics in Organometallic Chemistry, vol 32.]

46. Motterlini R, Otterbein LE: The therapeutic potential of carbon monoxide. Nat. Rev. Drug Discovery 2010, 9:728-743.

- This review presents an overview of the potential of carbon monoxide for medicinal applications as well as showing the limitations of the current CORMs.

47. Zobi F, Blacque O, Jacobs RA, Schaub MC, Bogdanova AY: 17 e- rhenium dicarbonyl COreleasing molecules on a cobalamin scaffold for biological application. Dalton Trans. 2011:DOI: 10.1039/c1031dt10649j, and references therein. 
48. Zobi F, Degonda A, Schaub MC, Bogdanova AY: CO Releasing Properties and Cytoprotective Effect of cis-trans- $\left[\operatorname{ReII}(\mathbf{C O})_{2} \mathbf{B r}_{2} \mathbf{L}_{2}\right]_{n}$ Complexes. Inorg. Chem. 2010, 49:7313-7322.

49. Dougan SJ, Habtemariam A, McHale SE, Parsons S, Sadler PJ: Catalytic organometallic anticancer complexes. Proc. Natl. Acad. Sci. U.S.A 2008, 105:11628-11633.

- This paper presents the first in-depth study of a catalytic organometallic anticancer compound.

50. Alberto R: Organometallic Radiopharmaceuticals. In Medicinal Organometallic Chemistry. Edited by Jaouen G, Metzler-Nolte N: Springer-Verlag; 2010:219-246. Topic in Organometallic Chemistry, vol 32.]

- This book chapter is the most comprehensive review on the use of organometallic compounds for radiopharmaceutical purposes. 